UDC 811.111

DOI: $10.17223 / 24109266 / 8 / 9$

\title{
CLASSIFICATION OF WRITTEN TRANSLATION SKILLS FOR ENGLISH LEGAL DISCOURSE
}

\author{
N.N. Sergeeva, A.N. Bazueva \\ Ural State Pedagogical University (Yekaterinburg, Russian Federation) \\ E-mail: snatalia2010@mail.ru
}

\begin{abstract}
The article deals with the content of notions "English legal discourse", "translation difficulties", "translation strategy", "translation tactics", "translation skills". Description is given of the complex of written translation strategies for English legal discourse. The authors suggest developing groups of translation skills at pre-translation, translation and post- translation stages.

Keywords: English legal discourse; translation difficulties; translation strategy; translation tactics; translation skills.
\end{abstract}

\section{Introduction}

Translation represents a complex form of speech activity. This activity is impossible without specific knowledge, skills and personal qualities, which constitute translator's competence. Translation skills are central in the structure of translator's competence, which represents a synthesis of theoretical knowledge and practical actions performed on the basis of this knowledge.

The authors studying the methodological issues of translation teaching offer different sets of translation skills, classifying them with reference to the stage of work on translation [1]:

- skills to overcome linguistic and discourse difficulties at the pretranslation stage ("understanding and interpretation");

- skills to overcome linguistic and discourse difficulties at the translation stage ("producing the translation of the text");

- skills of editing and assessing the translated text, analyzing the problems of translation and ways of overcoming them (post-translation stage "checking and assessing the translation product").

Some authors divide translation skills into monolingual and bilingual, depending on the use of language. In addition, authors offer a set of translation skills depending on the goals of learning methodology [2].

\section{Classification methodology \\ for English legal discourse written translation skills}

The theoretical research is based on the fundamental assumptions of the activity theory of general psychology (L.S. Vygotsky, P.Ya. Galperin, 
A.N. Leontiev, S.L. Rubinstein etc.); theory of speech acts (P. Searle), fundamental assumptions of the theory of forming cross-cultural competence in teaching foreign languages (N.D. Galskova, E.I. Passov and etc.); different aspects of discourse (V. Karasik, N.D. Arutyunova, A.P. Chudinov etc.), as well on the theoretical assumptions of written speech practical application and techniques of translation (L.S. Barkhudarov, V.N. Komissarov, L.K. Latyshev, R.K. Minyar-Beloruchev, A.D. Shveitser etc.). Analysis of pedagogical, psychological, and linguistic literature, as well as synthesis and generalization form the methodological basis of the research.

\section{Research and results}

In this research English legal discourse is understood as a set of texts generated in the process of written communication in the field of law. As for the teaching of translating English legal discourse, it is important to take into account its specific nature, which manifests itself in linguistic and discursive features. The linguistic peculiarities are shown mainly at the vocabulary lexical level (use of terms, clichés, general vocabulary of legal importance, Latin loan words, abbreviations, etc.), and at the level of grammar (ways of expressing obligation and conditions, extensive use of complex adverbs (whereby, hereof), predominance of the passive voice, etc.). The discourse features are justified with the formality of communication, written information transfer channel, distant location of the communication participants, and with the peculiarities of the national legal system.

The existing approaches to the interpretation of the "translation" concept focus on different aspects of this phenomenon. One of them focuses on the sociocultural aspects; others focus on the communicative aspects.

The scholars who follow the socio-cultural and communicative approach focus their study on the cultural elements or contextual aspects in order to carry out their analysis. This can be separated into two groups: those who work from a communicative point of view, focusing on extra textual aspects; and those who deal with translation from a socio-cultural point of view [3].

At present, this definition is considered from the sociolinguistic viewpoint that is reflected in the definition of "translation difficulties", by which we mean a set of problems caused by linguistic and discursive features of English legal discourse.

Difficulties of translation are determined by the essence of translation as a complex form of speech activity. They arise, first, on the account of differences between the systems of the source and target languages, which present the difficulties of linguistic nature. Moreover, in the process of the translation we must consider the facts that are beyond the scope of the language system and are directly related to a foreign culture. The latter causes the difficulties of discursive nature. 
Indeed, sources of legal translation difficulty include the systemic differences in law, linguistic as well as cultural differences. All these are closely related [4].

According to S. Tolstoy, the translator in the process of translating the text is facing the difficulties of lexical and grammatical nature [5].

From our point of view, the lexical and grammatical difficulties of translation relate to the linguistic features of English legal discourse. The prevalence of acronyms, abbreviations, extensive use of the terminology, and archaisms cause difficulties mentioned above.

However, in the translation process, we are dealing not only with the systems of the two languages, but also with a concrete speech act. When we talk about some translation discrepancies, we do not mean isolated words and sentences, but about a completely translated speech act. The translation process is greatly complicated not only by differences in the systems of two languages, but also by differences in the subjective perception of communicative act participants, who belong to different cultures. The translated text belongs to the two systems - the original culture and the culture of the recipient; in this case some of the concepts and phenomena are not always the same in their cultures.

However, legal systems are peculiar to the societies in which they have been formulated. Each society has different cultural, social and linguistic structures developed separately according to their own conditioning. Legal concepts, legal norms and application of laws differ in each individual society, reflecting the differences in that society. Legal translation involves translation from one legal system into another. Unlike pure science, law remains a national phenomenon. Each national law constitutes an independent legal system with its own terminological apparatus, underlying conceptual structure, rules of classification, and sources of law, methodological approaches and socioeconomic principles [6]. This has implications for translation when communication is channeled across different language and culture.

There is a vast culture that the translator should take into account in order to undertake linguistic transfer: training in linguistics, literature, history and culture. Moreover, one must not forget that translation exists in order to transmit the original meaning of a text to a different language avoiding cultural prejudices, which may lead us to change the text we are translating. Finally, the job of the translator consists in communicating, even though what we are translating belongs to two linguistically and culturally different systems, always respecting the fact that perfect synonymy does not exist in language [3].

It can be assumed that translation of a legal text is impossible without taking into account the cultural traditions of both the original language and the language in which the translation is done. 
In general, the activity, which is directed to solving the problems of translation, is called translation strategy. Translation strategies are the subject of research in a methodological science, educational psychology, and psycholinguistics. In accordance with the definition given in the dictionary of methodological terms, a strategy is one of the ways of acquisition, preservation and use of information to achieve a particular purpose [7].

From the psycholinguistics point of view, a strategy is "patterns of decision-making in the course of human cognitive activity" [8].

Our analysis of Russian and foreign literature on the studied problem shows that the term may be used in the meaning of a plan of activity (T.Yu. Ternovykh, 2007; T.A. Sokolova, 2009;), algorithm of actions, the general direction of activity (J. Burner, 1977; A.E. Mikhina, 2009), a set of actions, goal-oriented actions (N.G. Mikhailova, 2008; A.N. Rossinskaya, 2009).

Written translation strategy of English legal discourse is a method of overcoming the difficulties of translation at the pre-translation, translation and post-translation stages. The strategies are implemented through tactics. Under translation tactics, we mean a set of sequential actions organized under the optimal parameters to resolve translation difficulties at all stages.

Nowadays, there is no uniform typology of translation strategies in linguistic science. It is advisable to take into account the specifics of translation as a complex form of speech activity. Such definitions as "activity" and "activity approach" are basis to foreign language teaching methodology [9]. Activity approach is highlighted in the works of A.N. Leont'ev, 1977, A.A. Leont'ev, 1997, I.A. Zimnyaya, 1981, 1999. The most common understanding of the activity is "its interpretation as a concrete historically conditioned way of being, human being" [10].

Activities are controlled by human needs. If we consider human activities in terms of the need for communication when dealing with issues related to the translation, we are interested in bilingual speech activity. From this aspect, I.A. Zimnyaya and V.I. Ermolovich define "translation" as a continuous process of reflection (the formation and formulation of the perceived thought - understanding the meaning of communication in one language and the formation and formulation of statements in a different language [11].

Speech activity is implemented in four kinds, namely: listening, speaking, reading and writing. Translation brings together all the components of speech activity. In case of the dominance of certain kinds of speech activity, one can single out different kinds of translation: Reading and Writing are dominating during written translation. In case of the dominance of certain kinds of speech activity, different kinds of translation are distinguished: Reading and Writing prevail in written translation. In this aspect, I.A. Zimnyaya defines translation as "a continuous process" [12]. 
V.N. Komissarov divides the translation process into three stages: the interpretation of reality through the text, finding the invariant of translation, editing the product of translation [13].

Thus, taking into account the linguistic and discursive specifics of English legal discourse and the stages of translation, a complex of translation strategies of the legal discourse must include three global strategies:

- pre-translation analysis, consisting of local strategies of preparing for the translation, identifying information items and stylistic features of the text;

- making translation decisions and creating a product of translation containing the local strategies of selection of appropriate equivalents, and creating your own theme glossary of terminology;

- editing the translated text and generalizing translation experience covering local strategies of verification and correction of the text, analyzing the current translation problems and the way to overcome them, and systematizing successful translation solutions.

Possessing knowledge about specifics of the legal discourse, a translator applies appropriate skills to realize the strategies. Leontyev defines a skill as "the ability to carry out a particular activity at the optimal parameters of this action that is the best way, so that the implementation of this action is appropriate for the purpose and conditions of its progress" [14: 136]. After the definition of A.A. Leontyev, we define the translation skills as the ability to carry out this or that speech act at the optimal parameters corresponding to the objectives and tasks of the translation.

In other words, to translate legal discourse written texts from English into Russian it is necessary to perform certain actions purposefully, using the translation tactics, and these actions gradually become skills.

Such authors as L.K. Latyshev [15], V.N. Komissarov [13], etc., offer a different set of translation skills. Taking into account the working conditions with a class of law students and the stages of work on the translation, there are the following groups of translation skills:

- skills to overcome linguistic and discourse difficulties at the first stage of the translation - "understanding and interpretation": to carry out various types of information research on the subject of the text by means of electronic search engines; to determine logical-semantic orientation in the text; to identify key words and terms in the text; to use a variety of electronic dictionaries; to find the right lexical meaning of the word and term, collocation; to find non-equivalent vocabulary, abbreviations, Latinisms; to recognize grammatical transformations; to work with linguistic and cultural literature and translate socio-cultural information;

- skills to overcome linguistic and discourse difficulties at the stage translation ("the product of the translation of the text"): to use electronic bilingual dictionaries, machine automatic translation; to classify and struc- 
ture information; to perform grammatical and lexical transformations (techniques of antonymous and synonymous translation; techniques of translation transcription, transliteration, loan-translation, descriptive translation, translation commentary;

- skills of editing and assessing the translated text, analyzing the problems of translation and ways of overcoming them (translation stage - "testing and evaluation of the translation product"): to use electronic dictionaries; to use the systems of spelling checking; to use search engines and disciplinespecific sites, translation forums; electronic encyclopedias; to identify adequate translation and evaluate it in terms of the norms of the Russian language; to edit text.

This classification of translation skills is the most suitable for the construction of a method of teaching written translation strategies for students of non-linguistic universities.

\section{Conclusion}

To conclude, translation difficulties of English legal discourse include the systemic differences in linguistic and cultural aspects. A method of overcoming these difficulties is a translation strategy. The latter is implemented through tactics. Translation tactics are a set of sequential actions for overcoming translation difficulties at all stages of work on translation. In summary, the translation skills enable translators to carry out the operations necessary to successfully complete the translation process. There are three groups of translation skills: skills to overcome linguistic and discourse difficulties at the pre-translation stage ("understanding and interpretation"); skills to overcome linguistic and discourse difficulties at the translation stage ("producing the translation of the text"); and skills of editing and assessing the translated text, analyzing the problems of translation and ways of overcoming them (post-translation stage - "checking and assessing the translation product").

\section{References}

1. Sergeeva, N.N. and Bushmanova, Y.A. (2011). Professionally oriented foreign language communicative competence of the student of a technical college. Kazan Science. 8. Kazan: Kazan Publishing House. pp. 241-242.

2. Sergeeva, N.N. and Bushmanova Y.A. (2013). Model of development of foreign language communicative competence future programmers. Teacher education in Russia. pp. 81-83.

3. Betlem, Soler Pardo. Translation Studies: An Introduction to the History and Development of (Audiovisual) Translation. Available from: http://www.uax.es (accessed: 01.09.2016).

4. Cao, D. (2007). Translating law. Clevedon: Multilingual Matters. p. 191.

5. Tolstoj, S. (1957). Basics of Translation from English into Russian. Moscow. Nos. pp. 2324. 
6. Sarcevic, S. (1997). New Approach to Legal Translation. The Hague: Kluwer Law International. p. 13.

7. Azimov, Je.G. (2010). New Dictionary of methodological terms and opnyaty (theory and practice of language teaching). IKAR. pp. 97.

8. Zalevskaja, A.A. (2000). Introduction to psycholinguistics. Moscow: Rossijskij gos. gumanitarnyj un-t. pp. 45.

9. Pokhodzei, G.V. and Sergeeva, N.N. (2013). Methodology development of intercultural competence of foreign language future navigators in extracurricular work. Teacher education in Russia. pp. 146-152.

10. Leontyev, A.A. (1997). Psychology of communication. Moscow: Smysl. pp. 62.

11. Zimnyaya, I.A. and Ermolovich, V.I. (1981). Translation Psychology (textbook for higher translation rates). Moscow. pp. 99.

12. Zimnyaya, I.A. Core competencies - the result of a new paradigm of education. Available from: http://aspirant. Rggu/ru/article (accessed: 01.09.2016).

13. Komissarov, V.N. (2002). Modern Translation. Moscow: pp. 104.

14. Leontyev, A.A. (2003). Fundamentals of psycholinguistics. St. Petersburg: Lan '.

15. Latyshev, L.K. and Provotorov V.N. (2001). The structure and content of training translators in language high school: a teaching aid. Moscow: NVN-TEZAURUS. pp. 73.

Resived 02.09.2016.

\section{Information about the authors}

Sergeeva Natalia - Professor, Doctor of Education, Head of professionally-oriented language education, Ural State Pedagogical University (Yekaterinburg, Russian Federation). E-mail: snatalia2010@mail.ru

Bazueva Anna - postgraduate student, Ural State Pedagogical University (Yekaterinburg, Russian Federation). E-mail: snatalia2010@mail.ru 